\title{
Cuts and Guts: Public University Budget Hemorrhages
}

\author{
Don Steeples, Interim Dean, College of Liberal Arts and Sciences, \\ University of Kansas
}

$\mathrm{I}$ $\mathrm{t}$ is universally recognized that the cost of public higher education across the United States has skyrocketed in recent decades. Post-secondary education ex1 penses, primarily the cost of tuition have become less affordable for much of the population. This paper begins with a direct comparison of the cost for a semester of tuition in 1963 vs 2015. For purposes of this comparison, I have drawn upon my experience as an undergraduate engineering student at Kansas State University, where I first enrolled in 1963. Trends in state support for public higher education in Kansas are reviewed, as are changes in the level of state support nationwide. After this brief review of tuition costs and legislative support, I suggest a few conclusions can be drawn.

\section{"Old-Geezer" College Tuition Ex- penses Vs Today}

Since I enrolled at Kansas State University as a freshman in 1963, I am qualified to adopt the moniker, "Old Geezer." Table 1 (My Geezer's Experience) illustrates how tuition and residence hall costs at my alma mater have increased since I was a freshman in 1963. My tuition in 1963 was $\$ 107$ for 17 hours of engineering courses. When adjusted for inflation, those 17 hours would cost me $\$ 832$ in 2015 dollars. In contrast, the actual cost in fall 2015 at KSU will be $\$ 4,660$, an increase of more than five times the inflated cost. Similar results could be shown for The University of Kansas and many other public institutions.

While tuition costs at KSU have climbed over $4000 \%$ since 1963, residence hall living remains affordable for most segments of the population: the cost of

\section{Table 1}

\section{My Geezer's Experience}

Tuition \& Housing Expenses at K-State: 1963 vs 2015

\begin{tabular}{|l|c|c|c|}
\cline { 2 - 4 } \multicolumn{1}{c|}{} & $\begin{array}{c}1963 \\
\text { actual } \\
\text { cost }\end{array}$ & $\begin{array}{c}1963 \$ \$ \\
\text { inflated to } \\
2015 \$ \$\end{array}$ & $\begin{array}{c}2015 \\
\text { actual } \\
\text { cost }\end{array}$ \\
\hline Tuition (17 hours) & $\$ 107$ & $\$ 832$ & $\$ 4660$ \\
\hline Res Hall (20 meals/wk) & $\$ 600$ & $\$ 4663$ & $\$ 4215$ \\
\hline
\end{tabular}




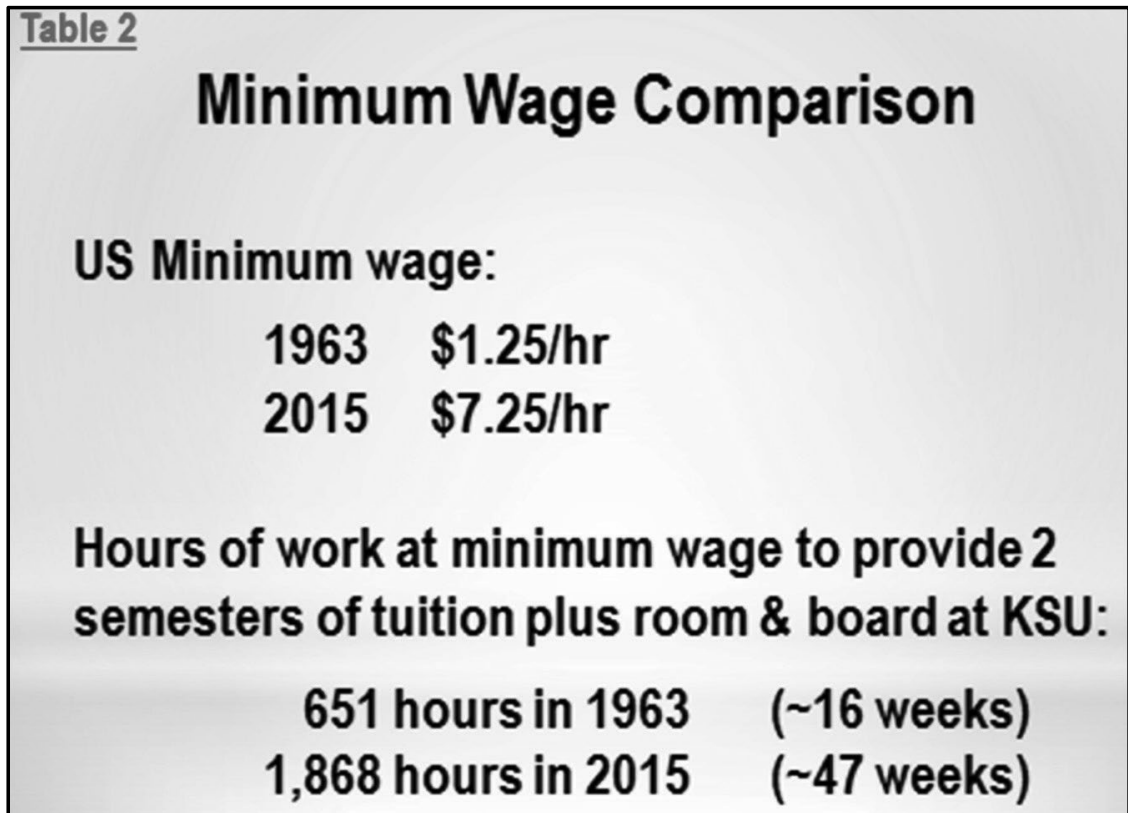

room and board at K-State has increased at a rate lower than general inflation. As shown in Table 1, inflation-adjusted 2015 residence hall rates were more than $\$ 400$ below the 1963 rate in current dollars. Residence hall rates remain a bargain relative to tuition at public universities in Kansas.

A closer look at decreased affordability is shown in Table 2 (Minimum Wage Comparison). The minimum wage in the U.S. was \$1.25 per hour in 1963 and in 2015 has increased to $\$ 7.25$ per hour. In 1963, a student who worked for 651 hours at minimum wage could earn enough money for two semesters of tuition and of residence hall living at KSU. In 2015, a student would have to work 1,868 hours at minimum wage to provide for two semesters of tuition and residence hall living. Consequently, it is no longer possible for a student to pay for all of the costs of a KSU degree with a minimum-wage summer job combined with a few hours per week of part-time employment during the school year.

One of the reasons that residence hall living has remained affordable is that the cost of food in the U.S. has risen much

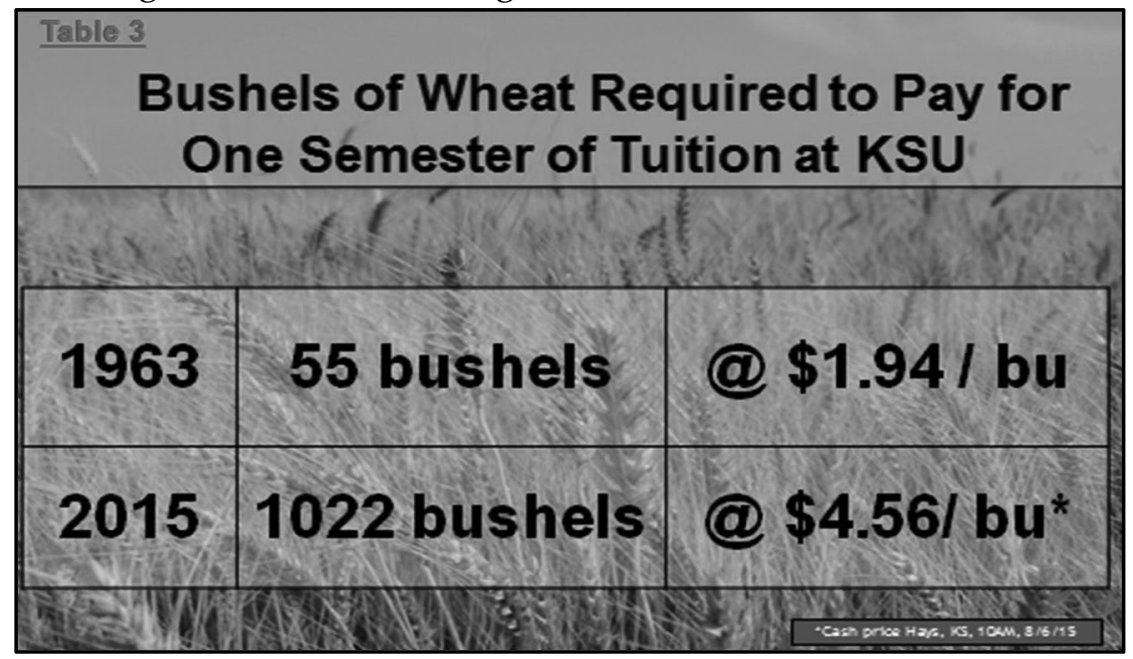


more slowly than inflation. My own undergraduate education at KSU was financed by selling wheat from a piece of land that my father let me farm when I was in high school. In 1963, selling 55 bushels of wheat at the national average local-elevator price would provide one semester of tuition at KSU. Based on the cash price for wheat in Hays, Kansas, at 10:00 AM on August 6, 2015, paying for one semester of KSU tuition would require more than a thousand bushels of wheat (Table 3, Bushels of Wheat...). While residence-hall living is a bargain relative to tuition, wheat is even more of a bargain.

\section{Kansas Public Higher Education}

\section{Budget Trends}

If we look at Table 4 (Kansas Regents and K-12 Funding), we see that in the decade between 2002 and 2012, State General Fund appropriations overall for public universities in Kansas increased by only $4.9 \%$. In that same period, total expenditures from the State General Fund increased by $36.5 \%$, with the largest percentage of increase going to Human Services (100.9\%). Looking at Table 5 (In-

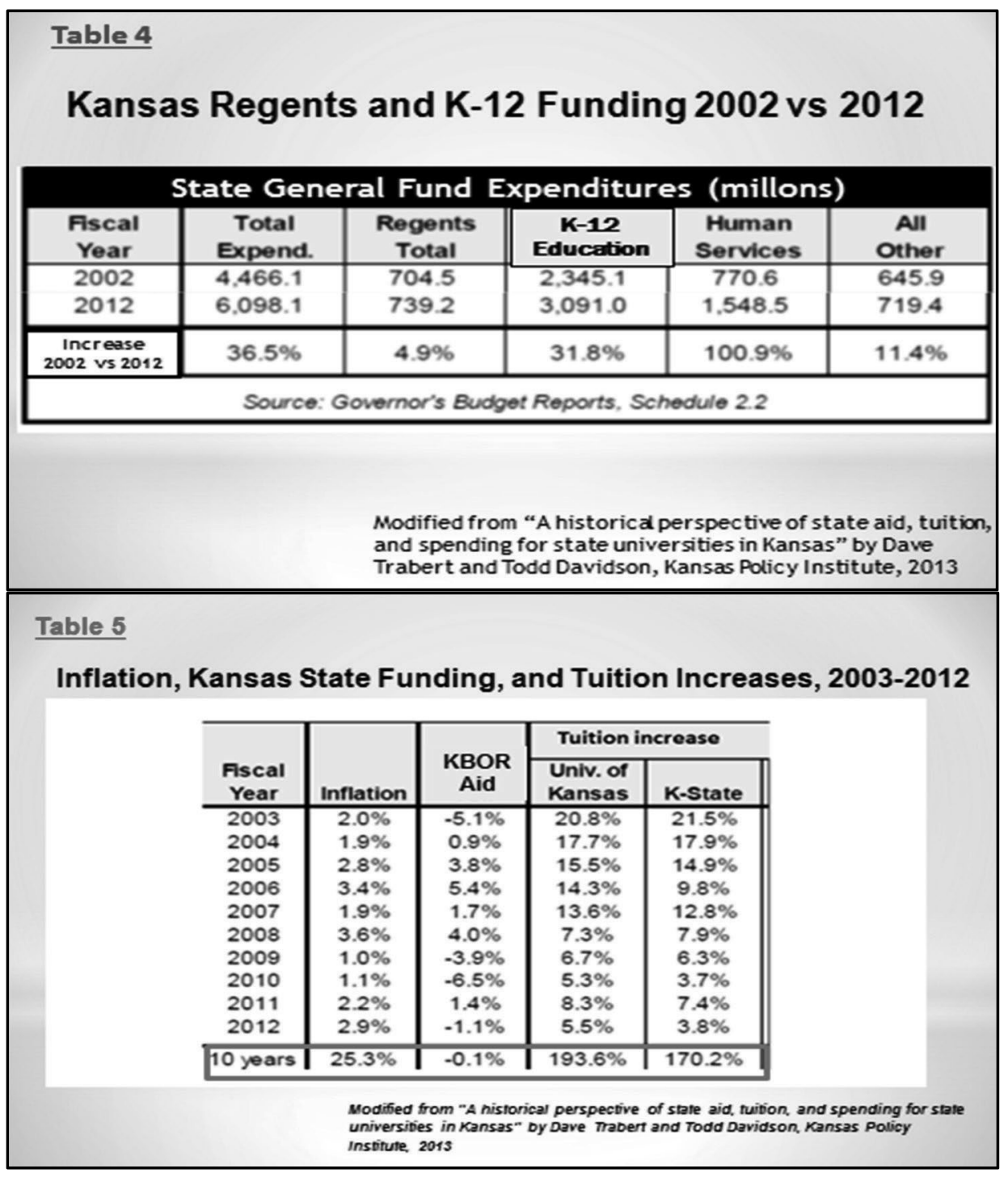


flation, Kansas State Funding, and Tuition Increases) we see that from 2003 to 2012, inflation in the U. S. totaled 25.3\%. In that same period, State support of Kansas public universities actually decreased by $0.1 \%$. To make up for this decrease in funding, tuition increased by $193.6 \%$ at The University of Kansas and by $170.2 \%$ at KSU.

Clearly, the budgets of KU and KSU have been balanced increasingly on the backs of students. Cuts in Kansas state-

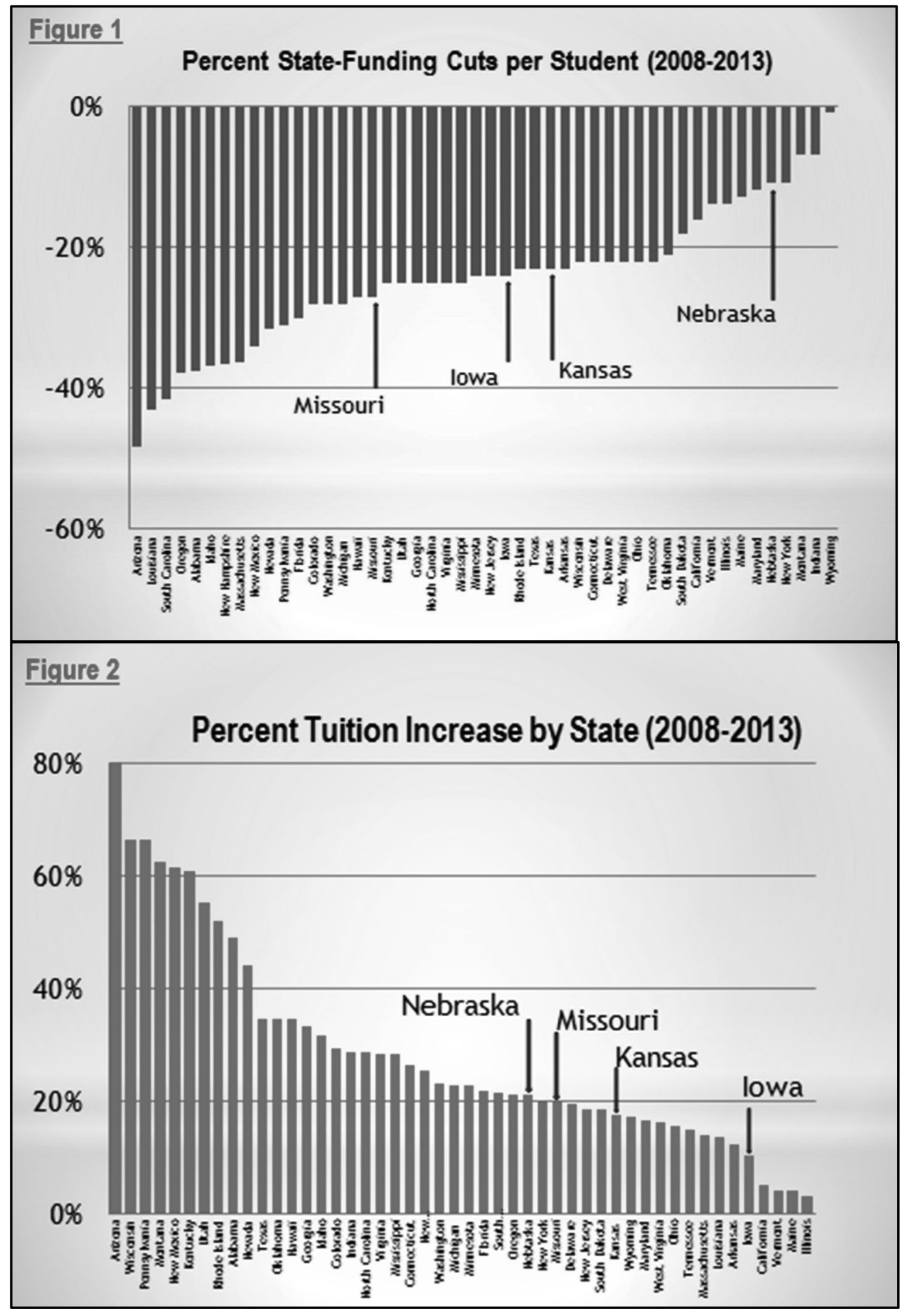




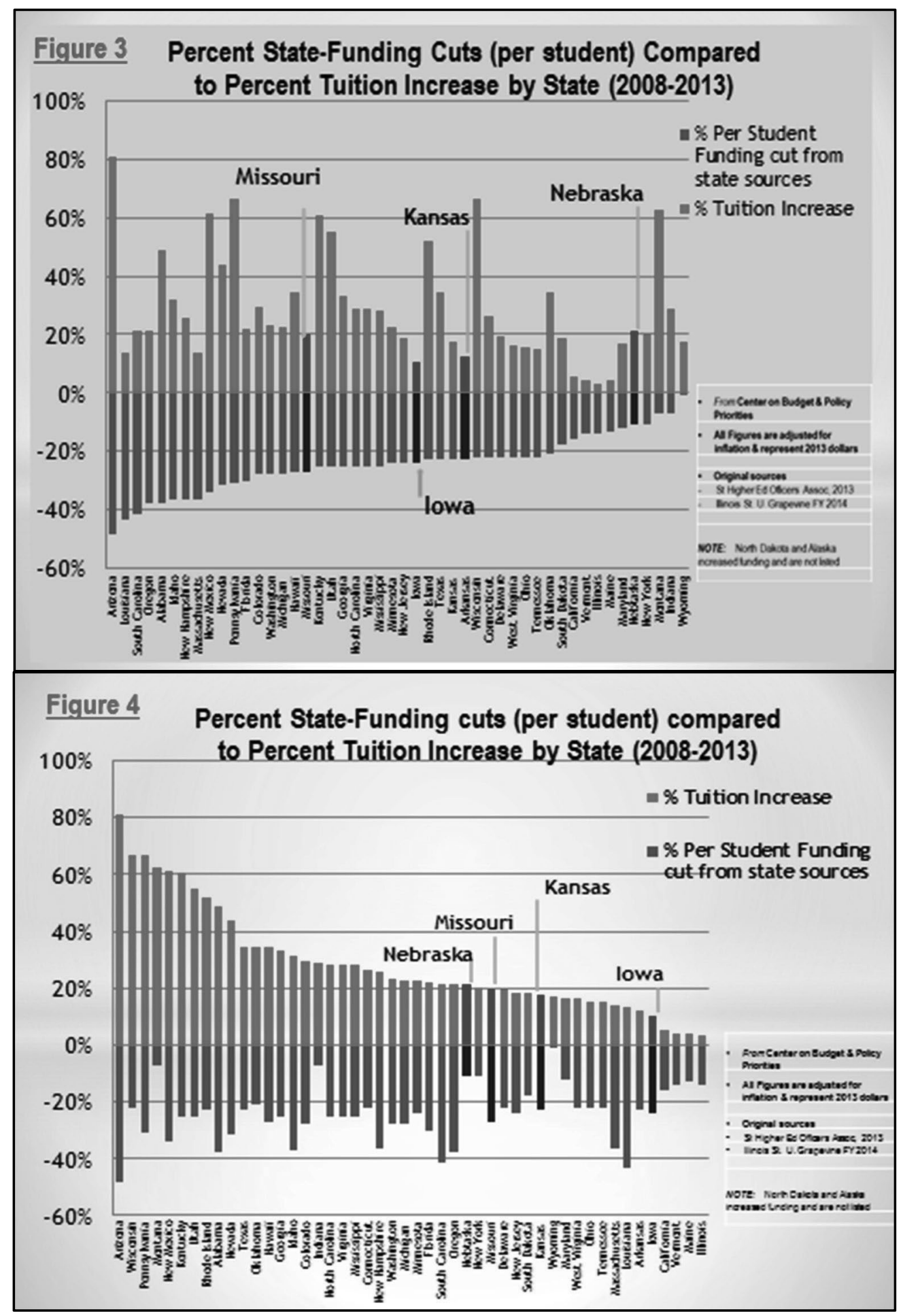

government funding have been offset by tuition increases. Based on the Kansas experience, it seemed reasonable to hypothesize that cuts in state-government funding for public universities across the U.S. have been mostly offset by tuition increases. Let's now examine the degree to which this is true across the whole U.S.

U.S. Public Higher-Education Budget Trends (2008-2013) 
The funding trends across the U.S. in the period from 2008 to 2013 have varied greatly (Figures 1-4). Only two states (Alaska and North Dakota) increased funding per student during the period. In contrast, Arizona, Louisiana, and South Carolina decreased per-student funding by more than $40 \%$ between 2008 and 2013. During the same window of time, Kansas, Missouri, and Iowa all decreased per-student funding by between $20-30 \%$; Nebraska decreased per-student funding by about $10 \%$.

As we have seen above, when the Kansas state government reduced funding, the Kansas Board of Regents responded by approving tuition increases that were essentially designed to fill the funding gap. Several other states followed a similar path. For example, Arizona cut per-student funding by about $48 \%$ and increased tuition by $80 \%$. Wisconsin, Pennsylvania, Montana, New Mexico, and Kentucky all had tuition increases of more than $60 \%$ between 2008 and 2013. (At the opposite end of the spectrum are Louisiana and South Carolina, which cut per-student funding by more than $40 \%$, but only increased tuition by about $14 \%$ and $21 \%$ respectively.)

Overall, state per-student funding is generally a picture of less per-student public financial support amid tuition increases. The tuition increases may or may not partially replace, totally replace, or exceed the cuts in public funding.

Declining public financial support for higher education on a per-student basis has led to increased tuition costs in Kansas and surrounding states. In the face of this fact, administrators will be forced to make difficult, but wise, decisions on where to apply budget cuts at their institutions. This will necessitate a thoughtful review of resource deployment...as well as the development of a healthy dose of intestinal fortitude.

\section{Conclusions}

Since 1963:

1. In Kansas, tuition has risen 5X faster than board and room

2. In Kansas, tuition has gone up $3 X$ faster than the U.S. minimum wage

3. Students can no longer pay for college with just a summer job

Since 2002:

1. Kansas' state budget has gone up $8 \mathrm{X}$ faster than its support of highereducation

2. Only two U.S. states have increased per-student funding since 2008

3. Tuition increases do not necessarily offset decreased state support

4. Decreased state support does not automatically mean tuition goes up 